\title{
ELEMEN SIMETRIS DAN SIMETRIS DIPERUMUM PADA RING DENGAN INVOLUSI
}

\author{
Titi Udjiani SRRM \\ Departemen Matematika, Fakultas Sains dan Matematika, Universitas Diponegoro \\ Email : udjianititi@yahoo.com,
}

\begin{abstract}
The definition of symmetric element in a ring with unity and equipped with involution can be generalized to generalized symmetric elements. But the properties of symmetric element not automatically can be generalized to generalized symmetric elements. In this paper, we discuss the property of symmetric element which can or cannot be generalized to generalized symmetric elements. Because of at least there is an element of symmetric and generalized symmetric elements which have the generalized Moore Penrose inverse, so method in this paper is by establishing a relationship between symmetric element, generalized symmetric element and generalized Moore Penrose inverse of element.
\end{abstract}

Keywords: inverse, symmetric, involution.

Abstrak. Definisi elemen simetris pada ring dengan elemen satuan yang dilengkapi dengan involusi dapat diperumum menjadi elemen simetris diperumum. Akan tetapi tidak secara otomatis sifat sifat yang dimiliki oleh elemen simetris juga berlaku atau dapat diperumum pada elemen simetris diperumum. Tulisan ini membahas sifat sifat elemen simetris baik yang dapat maupun tidak dapat diperumum pada elemen simetris diperumum. Oleh karena setidaknya terdapat sebuah elemen dari elemen simetris dan simetris diperumum memiliki invers Moore Penrose diperumum, maka metode yang digunakan pada tulisan ini adalah dengan membangun hubungan antara elemen simetris, simetris diperumum dan invers Moore Penrose diperumumnya.

Kata kunci: invers, simetris, involusi.

\section{PENDAHULUAN}

Diketahui $R$ adalah ring dengan elemen satuan yang dilengkapi involusi "*". D. Mosic dan D.S.Djordjevic [2] dan Koliha JJ et.all. [3] mendefinisikan involusi "*" pada $R$ sebagai fungsi $a \in R \mapsto a^{*} \in R$ yang memenuhi

$$
\left(a^{*}\right)^{*}=a \quad(a+b)^{*}=a^{*}+b^{*} \quad(a b)^{*}=b^{*} a^{*}
$$

untuk setiap $a, b \in R$.

Tidak setiap elemen di $R$ yang dikenai operasi involusi menghasilkan dirinya sendiri. Fenomena ini oleh D. Mosic dan D.S.Djordjevic [1] digunakan untuk mendefinisikan elemen simetris di $R$. Elemen $a \in R$ disebut simetris jika memenuhi $a^{*}=a$. Himpunan elemen simetris di $R$ diberi simbol $R^{\text {sym }}$. 
Salah satu jenis invers pada ring adalah invers Moore Penrose diperumum. Menurut Titi [7] jika diketahui elemen $a, b \in R$, maka elemen $b$ disebut invers Moore Penrose diperumum dari $a$ apabila syarat syarat sebagai berikut dipenuhi :

$$
a b a=a, \quad(a b)^{*}=a b, \quad(b a)^{*}=b a .
$$

Selanjutnya invers Moore Penrose diperumum dari $a$ disimbolkan dengan $a_{g}^{+}$sedangkan $R_{g}^{+}$adalah symbol untuk himpunan elemen di $R$ yang memiliki invers Moore Penrose diperumumnya tidak selalu tunggal. . Himpunan invers Moore Penrose diperumum dari $a \in$ $R$ disimbolkan dengan $\left(a_{g}^{+}\right)^{-}$.

\section{PEMBAHASAN}

Telah dibahas pada Titi [4] Teorema 1 bahwa jika $a \in R_{g}^{+}$, maka $a^{*} \in R_{g}^{+}$dan $\left(a^{*}\right)_{g}^{+}=$ $\left(a_{g}^{+}\right)^{*}$ for each $a_{g}^{+} \in\left(a_{g}^{+}\right)^{-}$dan $\left(a^{*}\right)_{g}^{+} \in\left(\left(a^{*}\right)_{g}^{+}\right)^{-}$. Selanjutnya Titi [5] membangun Teorema 1 sebagai berikut :

Teorema 1. Diketahui $a \in R_{g}^{+}$. Jika $a$ adalah elemen simetris, maka $a a_{g}^{+}=a_{g}^{+} a$ untuk setiap $a_{g}^{+} \in\left(a_{g}^{+}\right)^{-}$

\section{Bukti :}

Oleh karena $a \in R_{g}^{+} \cap R^{s y m}$, maka dengan menggunakan definisi invers Moore Penrose diperumum dan involusi diperoleh $\left(a a_{g}^{+}\right)^{*}=\left(a a_{g}^{+} a a_{g}^{+}\right)^{*}=\left(a_{g}^{+} a a_{g}^{+}\right)^{*} a^{*}=\left(a^{*}\right)_{g}^{+} a^{*}\left(a^{*}\right)_{g}^{+} a^{*}=$ $a_{g}^{+} a a_{g}^{+} a=a_{g}^{+} a$ untuk setiap $a_{g}^{+} \in\left(a_{g}^{+}\right)^{-}$. Dilain pihak jika $a \in R_{g}^{+}$, maka $\left(a a_{g}^{+}\right)^{*}=a a_{g}^{+}$ untuk setiap $a_{g}^{+} \in\left(a_{g}^{+}\right)^{-}$. Dapat disimpulkan bahwa $a a_{g}^{+}=a_{g}^{+} a$ untuk setiap $a_{g}^{+} \in\left(a_{g}^{+}\right)^{-}$, sehingga Teorema 1 terbukti.

Teorema 1 tidak berlaku sebaliknya, sebagai contoh pada ring dengan elemen satuan $M_{2}\left(Z_{2}\right)$ yang dilengkapi dengan involusi transpose. Untuk $A=\left[\begin{array}{ll}1 & 1 \\ 0 & 1\end{array}\right] \in M_{2}\left(Z_{2}\right)$ diperoleh bahwa $A_{g}^{+}=\left[\begin{array}{ll}1 & 1 \\ 0 & 1\end{array}\right]$, sehingga $\mathrm{A} A_{g}^{+}=A_{g}^{+} \mathrm{A}$. Sementara A bukan elemen simetris di $M_{2}\left(Z_{2}\right)$ sebab $A \neq \mathrm{A}^{T}$. Selanjutnya dengan menambahkan sifat elemen simetris pada elemen $a \in R_{g}^{+}$ yang memenuhi $a a_{g}^{+}=a_{g}^{+} a$ untuk setiap $a_{g}^{+} \in\left(a_{g}^{+}\right)^{-}$, dapat diperoleh eksistensi elemen 
simetris $a$ di $R_{g}^{+}$. Dimotivasi oleh D. Mosic dan D.S.Djordjevic [2], selanjutnya Titi [5] mendapatkan hasil sebagai berikut.

Teorema 2. Diketahui $a \in R_{g}^{+}$. Elemen a adalah elemen simetris jika dan hanya jika $a^{*}=$ aaa $a_{g}^{+}$untuk setiap $a_{g}^{+} \in\left(a_{g}^{+}\right)^{-}$.

\section{Bukti :}

Oleh karena $a$ adalah elemen simetris, maka dengan menggunakan Teorema 1 diperoleh bahwa $a^{*}=a=a a_{g}^{+} a=a a a_{g}^{+}$untuk setiap $a_{g}^{+} \in\left(a_{g}^{+}\right)^{-}$. Sebaliknya jika $a^{*}=a a a_{g}^{+}$untuk setiap $a_{g}^{+} \in\left(a_{g}^{+}\right)^{-}$, maka $a=\left(a^{*}\right)^{*}=\left(a a a_{g}^{+}\right)^{*}=\left(a a_{g}^{+}\right)^{*} a^{*}$ then $=a a_{g}^{+} a a a_{g}^{+}=a a a_{g}^{+}=a^{*}$ untuk setiap $a_{g}^{+} \in\left(a_{g}^{+}\right)^{-}$.

Syarat perlu dan cukup yang lainnya agar suatu elemen yang mempunyai invers Moore Penrose diperumum merupakan elemen simetris dibahas pada Teorema 3 dibawah ini : D. Mosic dan D.S.Djordjevic [2], selanjutnya Titi [6].

Teorema 3. Diketahui $a \in R_{g}^{+}$. Elemen a adalah elemen simetris jika dan hanya jika aa= $a^{*} a$.

\section{Bukti :}

Jika $a$ adalah elemen simetris, maka $a a=a^{*} a$. Sebaliknya jika $a a=a^{*} a$, maka $a^{*}=$ $a^{*} a a_{g}^{+}=a a a_{g}^{+}$untuk setiap $a_{g}^{+} \in\left(a_{g}^{+}\right)^{-}$. Menurut Teorema 2, elemen $a$ adalah elemen simetris.

Berdasarkan definisi involusi telah dijelaskan bahwa jika $a, b \in R$, maka $(a b)^{*}=b^{*} a^{*}$. Selanjutnya dengan mengaplikasikan definisi involusi pada $a, b \in R^{\text {sym }}$ diperoleh $(a b)^{*}=$ $b a$. Untuk kejadian khusus, dimana $b=a$ kita mendapatkan $\left(a^{2}\right)^{*}=a^{2}$. Fenomena ini memotivasi D. Mosic dan D.S.Djordjevic [2], untuk mendefinisikan elemen simetris diperumum. Elemen $a \in R$ disebut elemen simetris diperumum jika memiliki sifat $\left(a^{n}\right)^{*}=$ $a^{n}$, untuk sebarang $n \in N$. Himpunan elemen simetris diperumum di $R$ diberi simbol $R^{g s y m}$. Selanjutnya muncul pertanyaan apakah sifat yang dimiliki elemen simetris dapat diperumum pada elemen simetris diperumum. 
Dengan mempertimbangkan bahwa setidaknya terdapat $1 \in R$ yang merupakan elemen simetris sekaligus elemen simetris diperumum dan mempunyai invers Moore Penrose diperumum, maka pembahasan perumuman sifat elemen simetris pada elemen simetris diperumum dilakukan dengan mengeksplore sifat sifat invers Moore Penrose diperumumnya.

Dengan menggunakan definisi elemen simetris diperumum, sifat elemen simetris yang disampaikan pada Teorema 1 dapat diperumum menjadi Lemma 3 sebagai berikut.

Lemma 3. Jika $a \in R^{g s y m}$ dan $n \in N$, maka $a^{n} a a^{*}=a a^{*} a^{n}$ dan $a^{n} a^{*} a=a^{*} a a^{n}$.

\section{Bukti :}

Oleh karena $a \in R^{g s y m}$, maka $a^{n} a^{*}=\left(a^{*}\right)^{n} a^{*}=\left(a a^{n}\right)^{*}=a^{*}\left(a^{*}\right)^{n}=a^{n} a^{*}$. Selanjutnya $a^{n} a a^{*}=a a^{*} a^{n} \operatorname{dan} a^{n} a^{*} a=a^{*} a a^{n}$.

Berikutnya untuk setiap elemen anggota dari $R_{g}^{+} \cap R^{g s y m}$ mempunyai sifat seperti yang disampaikan pada Teorema 4 sebagai berikut.

Teorema 4. Diketahui $a \in R_{g}^{+}$dan $n \in N$. Jika $a \in R^{g s y m}$, maka $a^{n} a_{g}^{+}=a_{g}^{+} a^{n}$ untuk setiap untuk setiap $a_{g}^{+} \in\left(a_{g}^{+}\right)^{-}$.

\section{Bukti:}

Karena $a \in R^{g s y m}$, maka $a^{n} a^{*} a=a^{*} a a^{n}$. Menggunakan Lemma 3 diperoleh bahwa $a_{g}^{+}\left(a_{g}^{+} a a_{g}^{+}\right)^{*} a^{n}=a_{g}^{+}\left(a_{g}^{+} a a_{g}^{+}\right)^{*} \quad a^{*} a \quad a_{g}^{+}\left(a_{g}^{+} a a_{g}^{+}\right)^{*} a^{n}=\left(a_{g}^{+}\left(a_{g}^{+} a a_{g}^{+}\right)^{*}\right)^{2} a^{*} a \quad a^{n}=$ $\left(a_{g}^{+}\left(a_{g}^{+} a a_{g}^{+}\right)^{*}\right)^{2} a^{n} a^{*} a=\left(a_{g}^{+}\left(a_{g}^{+} a a_{g}^{+}\right)^{*}\right)^{2} a^{n}\left(a^{*} a\right)^{2} \quad a_{g}^{+}\left(a_{g}^{+} a a_{g}^{+}\right)^{*}=$ $\left(a_{g}^{+}\left(a_{g}^{+} a a_{g}^{+}\right)^{*}\right)^{2} a^{*} a a^{n} a^{*} a \quad a_{g}^{+}\left(a_{g}^{+} a a_{g}^{+}\right)^{*}=a_{g}^{+}\left(a_{g}^{+} a a_{g}^{+}\right)^{*} a^{n} a^{*} a \quad a_{g}^{+}\left(a_{g}^{+} a a_{g}^{+}\right)^{*}=$ $a_{g}^{+}\left(a_{g}^{+} a a_{g}^{+}\right)^{*} a^{*} a a^{n} \quad a_{g}^{+}\left(a_{g}^{+} a a_{g}^{+}\right)^{*}=a_{g}^{+}\left(a_{g}^{+} a a_{g}^{+}\right)^{*} a^{*} a a^{n} a^{*} a\left(a_{g}^{+}\left(a_{g}^{+} a a_{g}^{+}\right)^{*}\right)^{2}=$ $a_{g}^{+}\left(a_{g}^{+} a a_{g}^{+}\right)^{*}\left(a^{*} a\right)^{2} a^{n}\left(a_{g}^{+}\left(a_{g}^{+} a a_{g}^{+}\right)^{*}\right)^{2}=a^{*} a a^{n}\left(a_{g}^{+}\left(a_{g}^{+} a a_{g}^{+}\right)^{*}\right)^{2}=$ $a^{n} a^{*} a\left(a_{g}^{+}\left(a_{g}^{+} a a_{g}^{+}\right)^{*}\right)^{2}=a^{n} a_{g}^{+}\left(a_{g}^{+} a a_{g}^{+}\right)^{*}$ untuk setiap $a_{g}^{+} \in\left(a_{g}^{+}\right)^{-}$.

$$
\begin{aligned}
& \text { Selanjutnya untuk setiap } a_{g}^{+} \in\left(a_{g}^{+}\right)^{-} \text {berlaku } a^{n} a_{g}^{+} \\
& =a^{n-1} a a_{g}^{+}\left(a a_{g}^{+} a a_{g}^{+}\right)^{*}=a^{n} a_{g}^{+}\left(a_{g}^{+} a a_{g}^{+}\right)^{*} a^{*}=a_{g}^{+}\left(a_{g}^{+} a a_{g}^{+}\right)^{*} a^{n} a^{*}=a_{g}^{+}\left(a_{g}^{+} a a_{g}^{+}\right)^{*}\left(a^{*}\right)^{n} a^{*}= \\
& a_{g}^{+}\left(a_{g}^{+} a a_{g}^{+}\right)^{*}\left(a^{n} a\right)^{*}=a_{g}^{+}\left(a_{g}^{+} a a_{g}^{+}\right)^{*} a^{*}\left(a^{n}\right)^{*}=a_{g}^{+}\left(a_{g}^{+} a a_{g}^{+}\right)^{*} a^{*} a^{n}=a_{g}^{+} a a_{g}^{+} a^{n}=a_{g}^{+} a a_{g}^{+} a a^{n-1} \\
& =a_{g}^{+} a a^{n-1}=a_{g}^{+} a^{n} \text {. }
\end{aligned}
$$


Dimotivasi oleh Teorema 1 dan Teorema 4 dapat dibangun Teorema 5 dibawah ini, yang merupakan perumuman dari sifat elemen simetris yang sudah disampaikan pada Teorema 2.

Teorema 5 Diketahui $a \in R_{g}^{+}$. Elemen $a \in R^{g s y m}$ jika dan hanya jika $\left(a^{*}\right)^{n}=a^{n} a a_{g}^{+}$untuk setiap $a_{g}^{+} \in\left(a_{g}^{+}\right)^{-}$

\section{Bukti :}

Dengan menggunakan Teorema 1 , untuk setiap $a_{g}^{+} \in\left(a_{g}^{+}\right)^{-}$berlaku $a^{n} a a_{g}^{+}=a^{n} a_{g}^{+} a=$ $a^{n-1} a a_{g}^{+} a=a^{n}=\left(a^{*}\right)^{n}$. Sebaliknya $\left(a^{*}\right)^{n}=a^{n} a a_{g}^{+}=\left(a a_{g}^{+} a\right)^{n} a a_{g}^{+}=\left(a a_{g}^{+}\right)^{n} a^{n} a a_{g}^{+}=$ $a a_{g}^{+} a^{n} a a_{g}^{+}=a a_{g}^{+}\left(a^{*}\right)^{n}=\left(a a_{g}^{+}\right)^{*}\left(a^{*}\right)^{n}=\left(a^{n} a a_{g}^{+}\right)^{*}=\left(\left(a^{*}\right)^{n}\right)^{*}=a^{n}$.

Lemma 6. Diketahui $a \in R_{g}^{+}$. Elemen a adalah elemen simetris diperumum, maka $a^{n} a=$ $\left(a^{*}\right)^{n} a$.

\section{Bukti:}

Dengan mengaplikasikan definisi elemen simetris diperumum maka Lemma 6 terbukti. Akan tetapi pernyataan pada Lemma 6 tidak berlaku sebaliknya. Sebagai contoh, untuk A = $\left[\begin{array}{ll}1 & 1 \\ 0 & 1\end{array}\right] \in M_{2}\left(Z_{2}\right)$, diperoleh bahwa $\mathrm{A}^{3} \mathrm{~A} \neq\left(\mathrm{A}^{T}\right)^{3} \mathrm{~A}$, sementara A elemen simetris diperumum di $M_{2}\left(Z_{2}\right)$ sebab $\mathrm{A}^{2}=\left(\mathrm{A}^{T}\right)^{2}$.

\section{KESIMPULAN}

Tidak semua sifat yang dimiliki oleh elemen simetris dapat diperumum pada elemen simetris diperumum. Hal ini ditunjukkan dengan membuktikan bahwa Teorema 3 tidak dapat diperumum pada Lemma 6. Sementara Teorema 1 dan 2 berturut turut diperumum menjadi Teorema 4 dan 5 .

\section{REFERENSI}

[1] D. Mosic dan D.S.Djordjevic, "Moore Penrose Invertible Normal and Hermitian Elements in Ring ", Linear Algebra Appl, vol. 431, pp. 732-745, 2009

[2] D. Mosic dan D.S.Djordjevic, " Partial Isometries and EP Elements in Rings with Involution ", A publication of the International Linear Algebra Society, vol. 18, pp. 761772,2009

[3] Koliha J.J., et al, “ ”, . Linear Algebra Appl., vol. 426, pp. 371-381, 2007

[4] T.Udjiani, B.Surodjo and S.Wahyuni , "Generalized Moore Penrose Inverse in Rings with Involution", Far East Journal of Mathematical Sciences, vol. 92, pp. 29-40, 2014 
[5] T.Udjiani, Kartono Suryoto R.Heri dan Priyo.S, "Generalized Moore Penrose invers of symmetric elements in rings with an Involution.", Far East Journal of Mathematical Sciences , vol.102, no. 8, pp. 1635-1646, 2017

[6] T. Udjiani, Harjito, Suryoto dan Nikken Prima, "Generalized Moore Penrose Inverse of Normal Elements in a Ring with Involution ”, IOP Conf. Series: Materials Science and Engineering , no. 300 012074, 2018.

[7] T Udjiani, S.Zaki, Suryoto dan Harjito , "Normal Elements On The Generalized Moore Penrose Inverse", IOP Conf. Series: Materials Science and Engineering, no. 1217 012067, 2019 